\title{
A Multi-Institutional Study on the Safety and Efficacy of Specimen Morcellation After Laparoscopic Radical Nephrectomy for Clinical Stage T1 or T2 Renal Cell Carcinoma
}

\author{
Simon D. Wu, M.D.,', O. Alex Lesani, M.D.,' Lee C. Zhao, M.D., William K. Johnston, M.D., \\ J. Stuart Wolf, Jr., M.D., ${ }^{2}$ Ralph V. Clayman, M.D., ${ }^{3}$ and Robert B. Nadler, M.D. ${ }^{1}$
}

\begin{abstract}
Introduction and Objective: Specimen morcellation during laparoscopic radical nephrectomy (LRN) for renal cell carcinoma (RCC) is controversial. We seek to evaluate the safety and efficacy of specimen morcellation and LRN for treatment of presumed malignant renal lesions.

Methods: We retrospectively reviewed all patients who underwent LRN at three academic institutions from 1996 to 2007. One hundred eighty-eight patients underwent specimen morcellation after LRN for enhancing solid or cystic renal masses.

Results: LRN was successfully performed on all the patients. Patient age ranged from 36 to 94 . One hundred sixty-seven patients were in clinical stage T1, 19 patients T2, and unknown in two. The specimen was manually morcellated within a Cook Lap Sac or Endocatch II bag under laparoscopic or direct observation. On histological review of morcellated specimens, 165 patients were confirmed to have RCC, 17 had an oncocytoma, and 2 had benign cysts. At least 13 patients with RCC were pathologically upgraded to stage T3. Mean operative time was 225 minutes (range 94-650). Mean hospital stay was 2.5 days (range 1-8). In patients with RCC, 11 developed recurrent disease with mean follow-up of 21 months (range 0.3-111). In one patient, a port site recurrence occurred in concert with renal fossa and lymph node metastases.

Conclusions: Intracorporeal mechanical morcellation after LRN appears to be safe and effective in clinical stage $\mathrm{T} 1$ and T2 RCC. This supports the use of morcellation as an alternative for intact specimen removal in properly selected patients.
\end{abstract}

\section{Introduction}

$\mathbf{M}$ ORCELLATION IN CONJUNCTION with laparoscopic radical nephrectomy (LRN) has been an area of controversy since Clayman et $\mathrm{al}^{1}$ described the initial LRN with morcellation in 1991. It makes sense to use the existing ports to morcellate and extract the specimen and preserve the integrity of a minimally invasive laparoscopic operation. Critics counter that morcellation does not allow for adequate tumor staging and therefore may impact the ability to enroll patients in clinical chemotherapy trials. There also is a concern over intraabdominal, port site, and extraction site tumor seeding. In this multiinstitutional study, we sought to evaluate the safety and efficacy of specimen morcellation in conjunction with LRN for presumed renal cell carcinoma (RCC).

\section{Materials and Methods}

Records of all patients who underwent LRN from 1996 to 2007 were retrospectively reviewed at three academic urology departments. All procedures using manual morcellation of kidneys suspected of containing clinical stage T1 or T2, N0 RCC were included in the analysis. Postoperative follow-up included physical exam, routine laboratory studies, as well as axial imaging with computed tomography or magnetic resonance imaging to evaluate for complications and recurrent or metastatic disease.

The specimen entrapment and morcellation technique varied between institutions but universally involved the basic principles of performing morcellation under direct and/or laparoscopic vision; this includes extensive draping around

\footnotetext{
${ }^{1}$ Department of Urology, Northwestern University Feinberg School of Medicine, Chicago, Illinois.

${ }^{2}$ Department of Urology, University of Michigan Medical Center, Ann Arbor, Michigan.

${ }^{3}$ Department of Urology, University of California Irvine Medical Center, Orange, California.
} 
the port site through which the morcellated specimen is delivered to prevent tumor spill and dissemination. The techniques of specimen entrapment and morcellation utilized at Northwestern University have been previously described. ${ }^{2}$ At the University of California, Irvine, morcellation is performed by placing the specimen into a LapSac (Cook Urological, Spencer, IN) that is delivered through the caudal most port site that has been enlarged to $20 \mathrm{~mm}$. This is followed by a triple draping of the surgical field around the port site. The neck of the LapSac is covered by a sterile adhesive drape, a fenestrated absorbent towel, and a nephrostomy drape. The neck of the LapSac is passed through a hole in each of these drapes. These precautions are taken to help prevent potential wound contamination by any spilled tumor cells. The tumor is then manually morcellated using a Sopher gynecological ring forceps that has $14 \times 45 \mathrm{~mm}$ reinforced jaws. After completion of morcellation, the surgeon and all other members of the surgical team who participated during morcellation regown and reglove.

The University of Michigan has utilized both an impermeable nylon sac (i.e., LapSac) with intracorporeal morcellation and later adopted the technique described by Landman et $\mathrm{al}^{3}$ which entails placing the specimen in a self-opening plastic sac (Endo Catch II; Autosuture, Norwalk, CT) and lengthening a port site incision until the sac contents can be seen (typically $2-4 \mathrm{~cm}$, depending on patient's body wall thickness). Specimen morcellation is then performed under direct observation above the abdominal wall. A fenestrated drape is used to protect the port site from potential seeding. Once the specimen has been extracted, the incision is irrigated with $200 \mathrm{~mL}$ of sterile water after the surgical team regown and reglove. Table 1 compares the variations in morcellation technique among the three institutions.

\section{Results}

One hundred eighty-eight patients underwent LRN for renal lesions suspicious for clinical stage T1 and T2, N0, M0 RCC. Seventy-four patients were female (40\%) and 113 male (60\%). Mean age was 62.6 (range 24-94). Preoperative clinical staging was $\mathrm{T}_{1} \mathrm{~N}_{0} \mathrm{M}_{0}$ in $167(89 \%)$ patients and $\mathrm{T}_{2} \mathrm{~N}_{0} \mathrm{M}_{0}$ in 19 $(10 \%)$. Clinical staging information was not available for two patients (Table 2).

None of the cases required conversion to an open procedure. Morcellation of renal tumor specimens occurred without spillage or perforation of the LapSac or EndoCatch II sack.
Morcellation time was not assessed. Mean operating time was 225 minutes (range 94-650 minutes). No gross tumor spillage occurred and no perforation of entrapment sacks was noted during morcellation.

Average tumor size was $4.9 \mathrm{~cm}$ (range 1.5-16). Histologic review of morcellated specimens revealed that $165(87 \%)$ patients had RCC, 17 (9\%) had oncocytomas, 2 (1\%) had benign cysts, and 1 had both transitional cell carcinoma and RCC. Thirteen $(7 \%)$ patients had a pathologic upgrade to $\mathrm{pT} 3$ (Table 2).

Thirty patients (16\%) experienced complications. Thirtyeight complications were reported overall (Table 3): 4 cardiac, 5 respiratory/thromboembolic events, 8 gastrointestinal, 14 renal/genitourinary, 2 neurologic, 4 postoperative bleeds, and 1 death. One extraction site wound infection occurred. One extraction site incisional hernia occurred. Mean hospital stay was 2.5 days (SD 1.6 days). Mean follow-up was 21.3 months (range $0-111$ ). Out of 11 recurrences (5.8\%), 10 were pulmonary or visceral recurrences and 1 in the tumor bed (Table 4). In one patient, a port site recurrence occurred in concert with renal fossa recurrence and lymph node metastases. There were no isolated port site recurrences. No cancerrelated deaths occurred during follow-up period.

\section{Discussion}

Laparoscopic nephrectomy was originally described by Clayman et $\mathrm{al}^{1}$ in 1991 . It was predicated on specimen morcellation to minimize employment of more invasive enlarged incisions on the abdomen. To that end, the LapSac and an electronic morcellator were developed. The latter is no longer commercially available. Since then laparoscopic radical or total nephrectomy has been widely accepted as an oncologically sound and safe technique. ${ }^{4-11}$ Advantages in analgesic use and recovery compared with open nephrectomy have been documented. ${ }^{6,8}$ Although the initial report of LRN described entrapment and morcellation of the kidney and tumor specimen, morcellation has not become a widely accepted practice.

From a technical standpoint, morcellation can be performed safely without increased risk of tumor spillage. First, the LapSac has been shown to be impermeable to tumor spillage. Urban and colleagues found no diffusion of bovine serum albumin, indigo carmine, or mouse bladder tumor cells into dialysate when LapSacs were used as a dialysis membrane. ${ }^{12}$ Deployment of the LapSac can be simply accom-

Table 1. Morcellation Techniques Used at Respective Institutions

\begin{tabular}{|c|c|c|c|}
\hline Institution & $\begin{array}{l}\text { University of } \\
\text { California, Irvine }\end{array}$ & University of Michigan & Northwestern University \\
\hline $\begin{array}{l}\text { Entrapment/extraction } \\
\text { port site }\end{array}$ & Most caudal & Most caudal & Most caudal \\
\hline Morcellation port site & Most caudal & Most caudal & Umbilical \\
\hline Entrapment sac used & LapSac & LapSac/Endocatch II & $\begin{array}{l}\text { LapSac secured to } \\
\text { Endocatch II carrier }\end{array}$ \\
\hline $\begin{array}{l}\text { Morcellation port site } \\
\text { incision length }\end{array}$ & $20 \mathrm{~mm}$ & $20-40 \mathrm{~mm}$ & $20 \mathrm{~mm}$ \\
\hline Draping & $\begin{array}{l}\text { Clear plastic adhesive drape } \\
\text { fenestrated absorbent towel } \\
\text { nephrostomy drape }\end{array}$ & Fenestrated drape & Sterile towels \\
\hline Morcellation instrument & Sopher clamp & Sopher clamp & Ring forceps \\
\hline
\end{tabular}


Table 2. Patient Characteristics and Select Perioperative Outcomes

\begin{tabular}{|c|c|}
\hline$n$ & 188 \\
\hline Mean patient age, year (SD) & $62.6(13.5)$ \\
\hline Number of females (\%) & $74(39 \%)$ \\
\hline Mean tumor size, cm (SD) & $4.9(2.2)$ \\
\hline \multicolumn{2}{|l|}{ Clinical T stage $(\%)$} \\
\hline T1a & $75(40 \%)$ \\
\hline $\mathrm{T} 1 \mathrm{~b}$ & $92(49 \%)$ \\
\hline $\mathrm{T} 2$ & $19(10 \%)$ \\
\hline NA & $2(1 \%)$ \\
\hline Upstaged to pT3 & $13(7 \%)$ \\
\hline \multicolumn{2}{|l|}{ Fuhrman nuclear grade } \\
\hline I & $15(9 \%)$ \\
\hline II & $88(47 \%)$ \\
\hline III & $43(23 \%)$ \\
\hline IV & $10(5 \%)$ \\
\hline NA & $32(16 \%)$ \\
\hline \multicolumn{2}{|l|}{ Tumor histology (\%) } \\
\hline Clear cell RCC & $137(73 \%)$ \\
\hline Papillary RCC & $12(6 \%)$ \\
\hline Chromophobe RCC & $13(7 \%)$ \\
\hline Sarcomatoid RCC & $2(1 \%)$ \\
\hline Oncocytoma & $17(9 \%)$ \\
\hline TCC & $0(0 \%)$ \\
\hline Other & $2(1 \%)^{a, b}$ \\
\hline Benign cyst & $2(1 \%)$ \\
\hline NA & $3(2 \%)$ \\
\hline Tumor recurrence $(\%)$ & $11(5.8 \%)$ \\
\hline Mean time to recurrence, month & 19.4 \\
\hline \multicolumn{2}{|l|}{ Recurrence site } \\
\hline Morcellation port site & 1 \\
\hline Other port site & 0 \\
\hline Renal fossa & 1 \\
\hline Pulmonary/visceral & 10 \\
\hline Cancer related deaths & 0 \\
\hline Mean follow-up time, month (SD) & $21.3(22.0)$ \\
\hline Mean EBL, mL (SD) & $200(315)$ \\
\hline OR time, minute (SD) & $225(80)$ \\
\hline Mean length of stay, days (SD) & $2.5(1.6)$ \\
\hline
\end{tabular}

a Patient had both clear cell and papillary RCC.

${ }^{\mathrm{b}}$ Patient had both papillary RCC and TCC.

$\mathrm{NA}=$ not available; $\mathrm{SD}=$ standard deviation; $\mathrm{RCC}=$ renal cell carcinoma; $\mathrm{TCC}=$ transitional cell carcinoma; $\mathrm{EBL}=$ estimated blood loss.

plished as described by User and Nadler. ${ }^{2}$ With this technique, a LapSac is secured to the frame of an Endocatch II device after the original specimen sack is removed. The LapSac is then rolled tightly and the compressed frame and sack are drawn back into the cannula of the device. The device then can be redeployed as usual. The University of Michigan uses the morcellation technique described by Landman et al. ${ }^{3}$ Specimens are morcellated within an Endocatch II entrapment sack, which when compared with a LapSac is more flimsy. To ensure against tumor spillage, the authors modified their technique to widen the extraction incision to $3 \mathrm{~cm}$ and to only grasp and morcellate tissue that is protruding outside (i.e., extracorporeal) the wound. Endocatch II sack integrity was maintained in all cases, and no trocar site or local recurrences were noted in follow-up. ${ }^{3}$ Proper technique is required in all cases with morcellation under direct and/or laparoscopic vision to prevent perforation of the sack, as neither sack
TABle 3. Complications

\begin{tabular}{lc}
\hline Institution & Total \\
\hline Patients with complications (\%) & $30(16 \%)$ \\
Complication type & $4(11 \%)$ \\
Cardiac/MI/arrhythmia & $5(13 \%)$ \\
Respiratory/PE/DVT & $8(21 \%)$ \\
Gastrointestinal & $14(37 \%)$ \\
Urologic/renal & $2(5 \%)$ \\
Neurologic & $4(11 \%)$ \\
Postoperative bleed & $1(2 \%)$ \\
Death & $38(100 \%)$ \\
Total no. of complications &
\end{tabular}

$\mathrm{MI}=$ myocardial infarction; $\mathrm{PE}=$ pulmonary embolism; $\mathrm{DVT}=$ deep vein thrombosis.

is immune to perforation. Lastly adequate draping must be undertaken to prevent wound contamination, and all instruments, gowns, and gloves are changed at the end of morcellation before proceeding with the remainder of the surgery. ${ }^{13}$

Advantages in postoperative analgesic usage and convalescence are shown to favor laparoscopic over open nephrectomies. ${ }^{7,14,15}$ Nadler compared 33 patients who were prospectively enrolled and assigned in alternating fashion to receive hand-assisted, transperitoneal with morcellation or retroperitoneal laparoscopic nephrectomy. Intact specimen removal was performed in the hand-assisted and retroperitoneal groups. Patients who underwent morcellation had shorter hospital stays and time to normal daily activity. ${ }^{16}$ Camargo et $\mathrm{al}^{17}$ also demonstrated decreased narcotic requirement favoring morcellation versus intact specimen removal. Two studies that compared intact versus morcellated specimen removal showed no difference in postoperative status, but these studies were not randomized and had small numbers ${ }^{11}$ or did not compare similar populations. ${ }^{18}$

Critics also cite port site and peritoneal seeding as reasons against performing morcellation. However, only several case reports have shown this. Barrett et $\mathrm{al}^{19}$ described a solitary port site recurrence at 25 months in a patient with an advanced and large specimen (pT3N0M0 grade $4,862 \mathrm{gm}$ ). Two cases were reported by Castilho and associates. ${ }^{20,21}$ Both patients had pT1N0 grade 2 RCC that presented 5 and 12 months after LRN. Both patients presented with abdominal masses under the trocar sites and ascites. Risk factors cited as possibly contributing to recurrence included not using a LapSac specifically designed for morcellation, presence of ascites at time of nephrectomy, and unrecognized microperforations in the sack. Recent reviews on tumor seeding and port site metastases in urologic laparoscopy have shown this to be rare in the context of nephrectomy and morcellation done for presumed RCC. ${ }^{22-25}$ In Micali's survey of over 2600 laparoscopic radical nephrectomies, no tumor seeding was noted. ${ }^{22}$ Certainly, these numbers compare favorably with that of incisional scar metastases after open radical nephrectomy for RCC $(0.4 \%){ }^{24}$ In our multiinstitutional study, one port site metastases developed in concert with renal fossa and lymph node recurrence. Ten out of the 11 recurrences were either pulmonary or visceral in location. This is also consistent with reported data. $4,5,7,8,22,23$

Concern remains, however, regarding loss of pathologic staging with specimen morcellation. ${ }^{26}$ Preoperative 
Table 4. Patients with Recurrent Disease

\begin{tabular}{|c|c|c|c|c|c|c|c|c|c|}
\hline Age & Gender & $\begin{array}{l}\text { Clinical } \\
\text { stage }\end{array}$ & $\begin{array}{l}\text { Multiple } \\
\text { tumors }\end{array}$ & $\begin{array}{l}\text { Tumor } \\
\text { size }(\mathrm{cm})\end{array}$ & $\begin{array}{c}\text { Pathologic } \\
\text { stage } \\
\text { upgrade }\end{array}$ & Histology & Grade & $\begin{array}{l}\text { Time to } \\
\text { recurrence } \\
\text { (months) }\end{array}$ & $\begin{array}{l}\text { Location of } \\
\text { recurrence }\end{array}$ \\
\hline 78 & M & $\mathrm{T} 1 \mathrm{~b}$ & No & 6 & - & Clear cell & 2 & 18.8 & Lung \\
\hline 39 & $\mathrm{~F}$ & $\mathrm{~T} 1 \mathrm{~b}$ & Yes & 5 & - & Clear cell & 4 & 1.5 & Lung \\
\hline 51 & M & $\mathrm{T} 1 \mathrm{~b}$ & No & 5 & - & Clear cell & 2 & 37.1 & Lung \\
\hline 54 & M & $\mathrm{T} 1 \mathrm{~b}$ & No & 6.8 & - & Clear cell & 4 & 42.7 & Brain \\
\hline 75 & $\mathrm{~F}$ & $\mathrm{~T} 1 \mathrm{a}$ & No & 2.5 & - & Clear cell & 3 & 7.5 & Bone \\
\hline 61 & M & $\mathrm{T} 1 \mathrm{~b}$ & No & 5.5 & - & Clear cell & 3 & 45.7 & Lung \\
\hline 76 & M & T1a & No & 3.5 & - & Clear cell & 2 & 29.5 & Larynx \\
\hline 61 & $\mathrm{~F}$ & $\mathrm{~T} 2$ & No & 8 & T3a & Clear cell & 4 & 6.3 & Lung \\
\hline 40 & $\mathrm{M}$ & $\mathrm{T} 2$ & No & 7.3 & T3a & Clear cell & 3 & 7.3 & $\begin{array}{l}\text { Renal fossa, port site, } \\
\text { lymph node }\end{array}$ \\
\hline 65 & $\mathrm{~F}$ & $\mathrm{~T} 2$ & No & 8 & T3a & Clear cell & 3 & 10.9 & Contralateral kidney \\
\hline 80 & $\mathrm{~F}$ & $\mathrm{~T} 2$ & No & 13 & T3a & Clear cell & 4 & 5.7 & Abdomen and bone \\
\hline
\end{tabular}

staging based on axial radiographic imaging (i.e., computed tomography or magnetic resonance imaging) is accurate but may under- or overstage tumors in $5 \%$ to $35 \%$ of cases. ${ }^{27}$ Distinguishing between T2 and T3a tumors may be especially problematic because of tumor size and lack of sensitive radiographic findings. ${ }^{28}$ Grade and histologic type can be reliably and accurately identified in morcellated specimens. ${ }^{27,29}$ Various methods of specimen preparation to enhance accuracy of pathologic evaluation after morcellation have been reported and demonstrate that accurate pathologic staging is possible. ${ }^{29}$ Indian Ink staining of the specimen after entrapment but before morcellation allows pathologic determination of surgical margin status. ${ }^{30}$ Needle core biopsy of intact specimen before morcellation is accurate in confirming histologic diagnosis. ${ }^{31}$ Pathologic staging may also be successfully accomplished when morcellation is performed through a slightly extended extraction incision allowing for removal of larger fragments. ${ }^{3}$ Additional prognostic factors such as microvascular invasion can be assessed in morcellated specimens, but renal sinus fat invasion may not be reliably determined. ${ }^{9,29,32}$ Renal sinus fat invasion, however, is often associated with other negative prognostic indicators (e.g., perirenal fat invasion, lymph node metastases) that may be reliably determined. ${ }^{29,33,34}$ Further, systematic models of sampling morcellated specimens have been developed to determine the amount of tissue to be examined to arrive at the diagnosis with a given degree of certainty. ${ }^{35}$

No clear evidence exists that pathologic staging information lost because of specimen morcellation affects clinical follow-up or survival. $4,5,7,8,13,14,36$ Specifically, recurrence-free survival, disease-free survival, and overall survival do not appear to be different between open and laparoscopic nephrectomy with morcellation. ${ }^{7-9,14}$ Reports of pathologic upstaging for clinical T1 RCC and its impact on prognosis have been conflicting at best. ${ }^{36,37}$ Roberts found that up to $31 \%$ of the patients diagnosed with clinical T1 RCC were upstaged to pathologic T3a. However, recurrence-free survival did not differ between patients with pT1 and pT3a (in this study, defined as microscopic perinephric fat invasion) RCC. ${ }^{36}$ This study implies that current tumor nodes metastasis staging for pT3a tumors with microscopic perinephric fat invasion may not always correlate with prognosis and absence of pathologic staging after morcellation may be, in some cases, more an academic concern rather than a clinical one. Svatek and colleagues ${ }^{37}$ found that $9 \%$ of the clinical T1 RCC were upstaged pT3a (excluding adrenal involvement). Unlike the Roberts' study, patients with clinical T1 tumors that were pathologically upstaged exhibited higher probability of disease recurrence and cancer-specific death. ${ }^{37}$ Finally, lack of durable and standardized adjuvant therapy also diminishes the impact of potential pathologic staging information lost with specimen morcellation. Even with advent of targeted antivascular agents in treatment of metastatic RCC, these agents are still under investigation for use in the adjuvant setting. ${ }^{38}$ Cohen and colleagues ${ }^{39}$ argue, however, that it is precisely for this reason patients should undergo intact specimen extraction to identify potential candidates to enroll in adjuvant therapy trials.

In our present multiinstitutional series, morcellation technique-related complications were rare, and the subsequent rare occurrence of metastatic disease could not be ascribed to morcellation. Operating time and length of hospitalization are also consistent with previously published LRN series. ${ }^{4,5,7,8}$ Thirty patients overall experienced complications $(16 \%)$ that are consistent with reported laparoscopic nephrectomy series. ${ }^{4-6,8,13}$ One perioperative death occurred. This patient also had cardiopulmonary complications after a relatively lengthy case (365 minutes) during a prolonged hospitalization of 14 days. Interestingly, only one extraction site incisional hernia was reported $(0.5 \%)$, despite upward force applied to the extraction site during the actual process of morcellation. This compares favorably to intact specimen extraction after laparoscopic nephrectomy that is associated with incisional hernias in up to $36 \%$ with a hand-assisted approach $^{16}$ and also reported rates of trocar site hernias $(0.02 \%-5 \%){ }^{40}$ Elashry et $\mathrm{al}^{41}$ found a $17 \%$ rate of incisional hernias when the intact specimen was extracted from a lower flank port-connecting incision.

Weaknesses of this study are the lack of prospective randomized comparison of intact versus morcellated specimen removal. Further, patient characteristics (e.g., body mass index, comorbidities) were not evaluated; these characteristics certainly can influence outcomes. Clinical staging (e.g., nodal status, tumor size) and pathologic information were missing for some patients. Lastly, a comprehensive study evaluating the benefits of morcellation should also include functional 
outcomes (i.e., postoperative pain scores, time to return to normal activity) in addition to oncologic ones.

\section{Conclusions}

Morcellation is a safe method of specimen extraction after laparoscopic total radical/total nephrectomy. Our data support that there is equivalent survival in the morcellated patient cohort compared with open nephrectomy. Concerns for inaccurate pathologic staging are offset by similar survival seen between open and laparoscopic nephrectomy with morcellation and the documented ability to obtain accurate histology, assess for lymphovascular invasion, and to still stage the disease given the size of morcellated pieces. It would appear that only in those cases that require very specific information about pathologic staging (e.g., research protocolsASSURE, S-TRAC, SORCE; qualification for adjuvant therapies, determining more intensive surveillance schedules, possibility of upper tract urothelial carcinoma) should morcellation not be performed.

\section{Disclosure Statement}

Dr. Wolf-Terumo Corp, consultant; Gyrus-ACMI, lecturer.

Dr. Clayman-Cook Urological, Consultant/Advisor; Applied Urology, Investment Interest; Cook Urological Inc., Royalty Affiliation; Greenwald Inc., Royalty Affiliation; Orthopedic Service Inc., (OSI) Royalty Affiliation; Galil Inc., Consultant/Advisor; Boston Scientific, Investigator; Vascular Technology Inc., Consultant/Advisor; Karl Storz Inc., Consultant/Advisor.

Dr. Nadler-Intuitive Surgical (da Vinci), Consultant or Advisor; Angio Dynamics, Consultant or Advisor.

\section{References}

1. Clayman RV, Kavoussi LR, Soper NJ, et al. Laparoscopic nephrectomy: Initial case report. J Urol 1991;146:278-282.

2. User HM, Nadler RB. Novel technique of renal entrapment for morcellation. J Urol 2003;169:2287-2288.

3. Landman J, Venkatesh R, Kibel A, Vanlangendonck R. Modified renal morcellation for renal cell carcinoma: Laboratory experience and early clinical application. Urology 2003;62:632-634; discussion 635.

4. Barrett PH, Fentie DD, Taranger LA. Laparoscopic radical nephrectomy with morcellation for renal cell carcinoma: The Saskatoon experience. Urology 1998;52:23-28.

5. Cadeddu JA, Ono Y, Clayman RV, et al. Laparoscopic nephrectomy for renal cell cancer: Evaluation of efficacy and safety: A multicenter experience. Urology 1998;52:773-777.

6. McDougall E, Clayman RV, Elashry OM. Laparoscopic radical nephrectomy for renal tumor: The Washington University experience. J Urol 1996;155:1180-1185.

7. Dunn MD, Portis AJ, Shalhav AL, et al. Laparoscopic versus open radical nephrectomy: A 9-year experience. J Urol 2000;164:1153-1159.

8. Chan DY, Cadeddu JA, Jarrett TW, Marshall FF, Kavoussi LR. Laparoscopic radical nephrectomy: Cancer control for renal cell carcinoma. I Urol 2001;166:2095-2099; discussion 2099-2100.

9. Portis AJ, Yan Y, Landman J, et al. Long-term followup after laparoscopic radical nephrectomy. J Urol 2002;167:12571262.
10. Rassweiler J, Fornara $\mathrm{P}$, Weber $\mathrm{M}$, et al. Laparoscopic nephrectomy: The experience of the laparoscopy working group of the German Urologic Association. J Urol 1998;160:18-21.

11. Gettman MT, Napper C, Corwin TS, Cadeddu JA. Laparoscopic radical nephrectomy: Prospective assessment of impact of intact versus fragmented specimen removal on postoperative quality of life. J Endourol 2002;16:23-26.

12. Urban DA, Kerbl K, McDougall EM, et al. Organ entrapment and renal morcellation: Permeability studies. J Urol 1993; 150:1792-1794.

13. Varkarakis I, Rha K, Hernandez F, Kavoussi LR, Jarrett TW. Laparoscopic specimen extraction: Morcellation. BJU Int 2005;95 Suppl 2:27-31.

14. Ono $Y$, Kinukawa T, Hattori R, et al. Laparoscopic radical nephrectomy for renal cell carcinoma: a five-year experience. Urology 1999;53:280-286.

15. Walther MM, Lyne JC, Libutti SK, Linehan WM. Laparoscopic cytoreductive nephrectomy as preparation for administration of systemic interleukin-2 in the treatment of metastatic renal cell carcinoma: A pilot study. Urology 1999;53:496-501.

16. Nadler RB, Loeb S, Clemens JQ, et al. A prospective study of laparoscopic radical nephrectomy for T1 tumors-is transperitoneal, retroperitoneal or hand assisted the best approach? J Urol 2006;175:1230-1233; discussion 1234.

17. Camargo AH, Rubenstein JN, Ershoff BD, et al. The effect of kidney morcellation on operative time, incision complications, and postoperative analgesia after laparoscopic nephrectomy. Int Braz J Urol 2006;32:273-279; discussion 279-280.

18. Hernandez F, Rha KH, Pinto PA, et al. Laparoscopic nephrectomy: Assessment of morcellation versus intact specimen extraction on postoperative status. J Urol 2003;170:412-415.

19. Fentie DD, Barrett PH, Taranger LA. Metastatic renal cell cancer after laparoscopic radical nephrectomy: Long-term follow-up. J Endourol 2000;14:407-411.

20. Castilho LN, Fugita OE, Mitre AI, Arap S. Port site tumor recurrences of renal cell carcinoma after videolaparoscopic radical nephrectomy. J Urol 2001;165:519.

21. Landman J, Clayman RV. Re: Port site tumor recurrences of renal cell carcinoma after videolaparoscopic radical nephrectomy. J Urol 2001;166:629-630.

22. Micali S, Celia A, Bove P, et al. Tumor seeding in urological laparoscopy: An international survey. J Urol 2004;171:21512154.

23. Lee BR, Tan BJ, Smith AD. Laparoscopic port site metastases: Incidence, risk factors, and potential preventive measures. Urology 2005;65:639-644.

24. Tsivian A, Sidi AA. Port site metastases in urological laparoscopic surgery. I Urol 2003;169:1213-1218.

25. Lesani OA, Zhao LC, Han J, et al. Safety and efficacy of laparoscopic radical nephrectomy with manual specimen morcellation for stage cT1 renal-cell carcinoma. I Endourol 2008;22:1257-1259.

26. Granberg CF, Krambeck AE, Leibovich BC, et al. Potential underdetection of $\mathrm{pT}(3 \mathrm{a})$ renal-cell carcinoma with laparoscopic morcellation. J Endourol 2007;21:1183-1186.

27. Rabban JT, Meng MV, Yeh B, et al. Kidney morcellation in laparoscopic nephrectomy for tumor: Recommendations for specimen sampling and pathologic tumor staging. Am J Surg Pathol 2001;25:1158-1166.

28. Sheth S, Scatarige JC, Horton KM, Corl FM, Fishman EK. Current concepts in the diagnosis and management of renal cell carcinoma: Role of multidetector ct and threedimensional CT. Radiographics 2001;21 Spec No:S237-S254. 
29. Landman J, Lento P, Hassen W, Unger P, Waterhouse R. Feasibility of pathological evaluation of morcellated kidneys after radical nephrectomy. J Urol 2000;164:2086-2089.

30. Meng MV, Koppie TM, Duh QY, Stoller ML. Novel method of assessing surgical margin status in laparoscopic specimens. Urology 2001;58:677-681.

31. Pautler SE, Hewitt SM, Linehan WM, Walther MM. Specimen morcellation after laparoscopic radical nephrectomy: Confirmation of histologic diagnosis using needle biopsy. J Endourol 2002;16:89-92.

32. Bishoff JT. Laparoscopic radical nephrectomy: Morcellate or leave intact? Definitely morcellate! Rev Urol 2002;4: 34-37.

33. Roos FC, Weirich J, Victor A, et al. Impact of several histopathological prognosticators and local tumour extension on oncological outcome in $\mathrm{pT} 3 \mathrm{~b} / \mathrm{c}$ N0M0 renal cell carcinoma. BJU Int 2009. Epub ahead of print.

34. Bedke J, Buse S, Pritsch M, et al. Perinephric and renal sinus fat infiltration in pT3a renal cell carcinoma: Possible prognostic differences. BJU Int 2009;103:1349-1354.

35. Meng MV, Koppie TM, Stoller ML. Pathologic sampling of laparoscopically morcellated kidneys: A mathematical model. J Endourol 2003;17:229-233.

36. Roberts WW, Bhayani SB, Allaf ME, et al. Pathological stage does not alter the prognosis for renal lesions determined to be stage T1 by computerized tomography. J Urol 2005;173: 713-715.

37. Svatek RS, Lotan Y, Herman MP, et al. The influence of clinical and pathological stage discrepancy on cancer specific survival in patients treated for renal cell carcinoma. I Urol 2006;176:1321-1325; discussion 1125.

38. Jonasch E, Tannir NM. Adjuvant and neoadjuvant therapy in renal cell carcinoma. Cancer J 2008;14:315-319.
39. Cohen DD, Matin SF, Steinberg JR, Zagone R, Wood CG. Evaluation of the intact specimen after laparoscopic radical nephrectomy for clinically localized renal cell carcinoma identifies a subset of patients at increased risk for recurrence. J Urol 2005;173:1487-1490.

40. Shalhav AL, Barret E, Lifshitz DA, et al. Transperitoneal laparoscopic renal surgery using blunt $12-\mathrm{mm}$ trocar without fascial closure. I Endourol 2002;16:43-46.

41. Elashry OM, Giusti G, Nadler RB, McDougall EM, Clayman $\mathrm{RV}$. Incisional hernia after laparoscopic nephrectomy with intact specimen removal: Caveat emptor. J Urol 1997;158: 363-369.

Address correspondence to: Robert B. Nadler, M.D. Department of Urology Northwestern University Feinberg School of Medicine 675 North St. Clair St.

Galter 20-150

Chicago, IL 60611

E-mail: r-nadler@northwestern.edu

\section{Abbreviations Used}

$\mathrm{EBL}=$ estimated blood loss

$\mathrm{LRN}=$ laparoscopic radical nephrectomy

$\mathrm{NA}=$ not available

$\mathrm{RCC}=$ renal cell carcinoma

$\mathrm{SD}=$ standard deviation

$\mathrm{TCC}=$ transitional cell carcinoma 